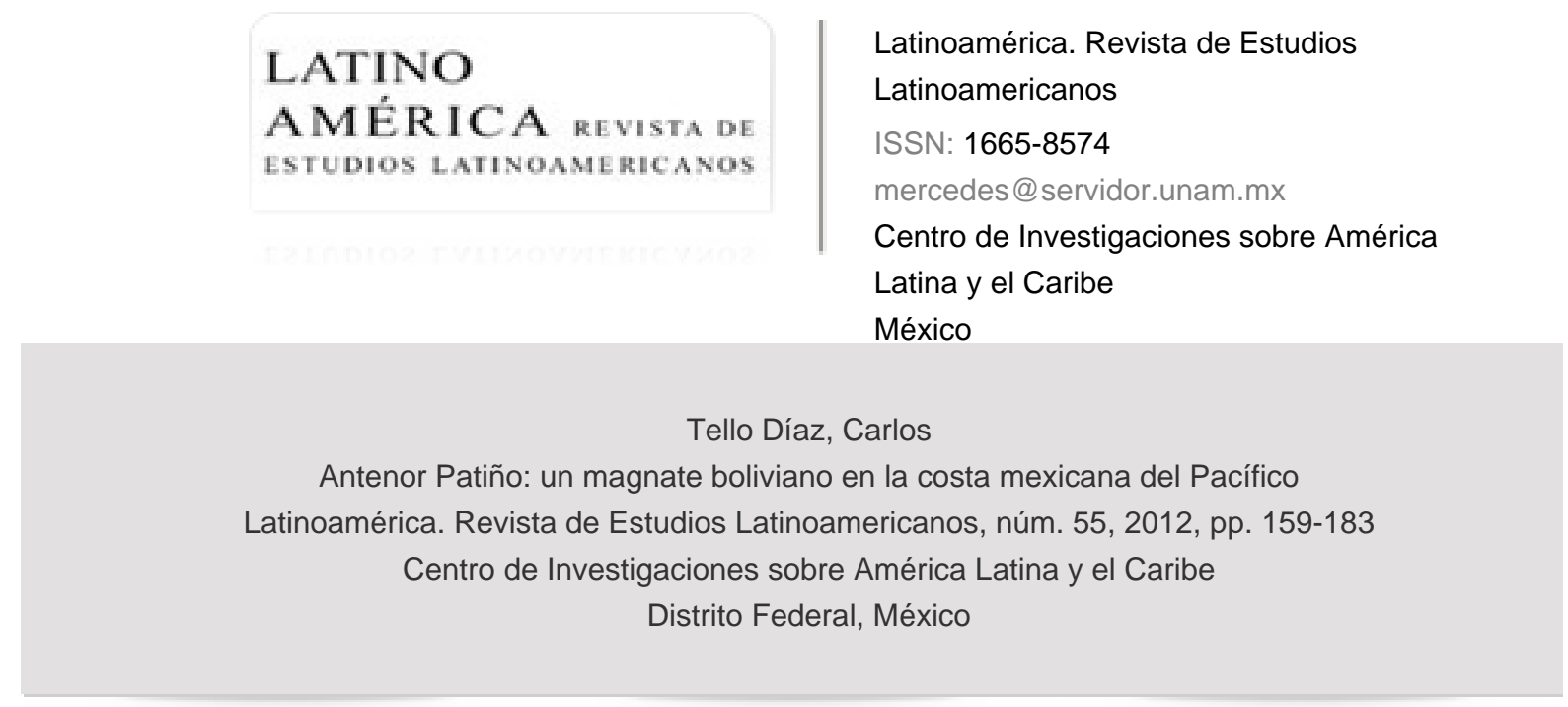

Disponible en: http://www.redalyc.org/articulo.oa?id=64024698007

- Cómo citar el artículo

- Número completo

- Más información del artículo

- Página de la revista en redalyc.org

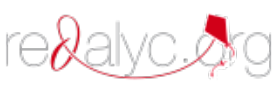

Sistema de Información Científica

Red de Revistas Científicas de América Latina, el Caribe, España y Portugal Proyecto académico sin fines de lucro, desarrollado bajo la iniciativa de acceso abierto 


\section{Antenor Patiño: un magnate boliviano en la costa mexicana del Pacífico}

Carlos Tello Díaz*

Resumen: La historia de las costas de Colima y Jalisco, en México, ha sido en gran parte determinada por un conjunto de factores azarosos, entre los que se destaca la inversión miIlonaria que, para justificar su domicilio conyugal en México, necesario a su vez para conseguir el divorcio de su primera esposa, tuvo que hacer el magnate boliviano Antenor Patiño en México. Patiño financió el aeropuerto de Playa de Oro, que hasta la fecha da servicio a esa parte de Colima y Jalisco, y fue el imán que atrajo al hombre que moldeó la costa con su interés por la conservación, el marido de su hija menor, James Goldsmith.

Palabras Clave: Derecho internacional privado, Inversión extranjera, Fideicomisos, Desarrollo turístico, Conservación ambiental.

ABSTRACT: The history of the coast of Colima and Jalisco in Mexico has been determined to a large extent by a series of accidental events, among which the most important is the big investment that the Bolivian millionaire Antenor Patiño had to make in Mexico in order to validate his conjugal address, which he needed to divorce his first wife. Patiño financed the international airport of Playa de Oro, which still serves that part of Colima and Jalisco, and attracted the man who fashioned the coast through his interest in conservation, the husband of his younger daughter, James Goldsmith.

Key Words: Private International Law, Foreign Investment, Trust Funds, Touristic Development, Environmental Preservation.

Centro de Investigaciones sobre América Latina y el Caribe, unam (carlos_tello_diaz@ yahoo.com.mx). 


\section{INTRODUCCIÓN}

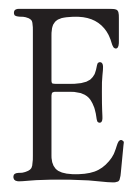

n su libro La terre et l'évolution bumaine, Lucien Febvre alertaba contra lo que llamaba la tesis determinista de la historia: "el viejo peligro, el viejo error de creer en la influencia directa, inmediata, brutal del clima sobre el hombre". ${ }^{1}$ Para él, la geografía, el clima, las regiones naturales eran, por el contrario, "simples conjuntos de posibilidades para las sociedades humanas, que los utilizan pero que no son determinadas por ellos".2. Había dos tipos de visiones, opuestas, antagónicas, respecto de la tesis que fundaba la historia sobre la tierra. Michelet estaba a favor ("sin una base geográfica, el pueblo, el actor histórico caminaría en el aire, como en esas pinturas orientales en las que falta el suelo"). ${ }^{3}$ Buffon, en cambio, estaba en contra ("los animales son, en muchos sentidos, producto de la tierra; sólo el hombre es en todo un producto del cielo"). ${ }^{4}$ Febvre estaba del lado de Buffon.

En medio de la tensión descrita por Febvre está la historia del sur de la costa de Jalisco. Esa región permaneció casi despoblada, durante siglos, a causa de la esterilidad del suelo, la sequedad del clima y, en general, el carácter poco accesible del territorio. La historia fue determinada por la geografía. Después aparecieron en la zona dos actividades características de fines del siglo xx, atraídas ambas por lo mismo, por un paisaje apenas perturbado por el hombre: la conservación ecológica y el desarrollo turístico, que durante la disputa que protagonizaron por el dominio del territorio concibieron posibilidades de paisaje completamente diferentes. La geografía fue determinada por la historia.

1 Lucien Febvre, La terre et l'évolution humaine: introduction géographique à l'bistoire, París, La Renaissance du Livre, 1922, p. 146.

2 Ibid., p. 204.

3 Citado por Febvre, op. cit., p.12.

4 Citado por Febvre, op. cit., p.10. 


\section{La llegada de Patiño a MÉxico}

La historia de la costa de Jalisco, sobre todo la región de Cuixmala, Careyes y Chamela, está íntimamente ligada a un hombre que nació en los Andes a fines del siglo xIx: Antenor Patiño. Era uno de los hombres más ricos del mundo, heredero de una fortuna legendaria en Bolivia. El fundador de la fortuna era su padre, Simón Patiño, originario del pueblo de Karasa, contemporáneo y congénere de Carlos Aramayo y Mauricio Hochschild, junto con quienes llegó a controlar la mayoría de las minas de estaño de Bolivia. Más tarde, él mismo compró las minas del sureste de Asia, en Tailandia y Malasia, por lo que controló durante décadas el mercado del estaño en el mundo, en un momento en que crecía la demanda de partes de autos y latas de alimentos en Europa y Norteamérica.

Simón Patiño falleció a una edad muy avanzada en la ciudad de Buenos Aires, el 20 de abril de 1947. Su hijo Antenor heredó entonces una de las grandes fortunas del mundo: "200 millones de dólares", de acuerdo con un periodista financiero del Sunday Times. ${ }^{5}$ Ocupaba por esos tiempos, dice uno de sus biógrafos, más vagamente, "el quinto o sexto lugar entre los primeros millonarios del mundo". ${ }^{6}$ Era en todo caso, afirma otra fuente, "uno de los hombres más ricos del mundo". 7 La Revolución de 1952 nacionalizó las minas de estaño que sustentaban su riqueza en Bolivia, pero ya para esos años él mismo era presidente de Thailand Tin Mines y de British American Tin Mines. Fue diplomático en Madrid, París y Londres, y más tarde en México, donde no tenía ya, sin embargo, el cargo de ministro de Bolivia. Estaba ahí por una razón totalmente distinta: su divorcio.

5 Ivan Fallon, Billionaire: The Life and Times of Sir James Goldsmith, Arrow Books, Londres, 1992, p. 87. Fallon es un periodista financiero en especial fiable respecto a las fortunas de las que habla.

6 Augusto Céspedes, Metal del diablo, Casa de las Américas, La Habana, 1965, p. 4. Céspedes no parece un autor confiable: su trabajo es muy desarticulado. Pero el dato ilustra el carácter legendario de la fortuna de Patiño. Su comentario sobre la riqueza de don Antenor, en todo caso, es respaldado por otro autor: "Su fortuna era igualada sólo por un puñado de familias: los Getty, los Hunt y, quizá, los Rothschild”. Geoffrey Wansell, Tycoon: The Life of James Goldsmith, Grafton Books, Londres, 1987, p. 64.

7 Time, 25 de enero, 1960. La nota de la revista anunciaba el segundo matrimonio de Patiño. 
En 1931, Antenor Patiño contrajo nupcias en Madrid, mediante el régimen de separación de bienes, con María Cristina de Borbón y Bosch-Labrus, quien era parte de la familia real de España. Antenor tenía entonces 35 años: había nacido en 1896 en Oruro, Bolivia, hijo de Simón Patiño, al que la gente llamaba el Rey del estaño. María Cristina, en cambio, tenía sólo 17 años: había nacido en 1913, hija del duque de Durcal - primo a su vez del rey Alfonso XIII-, una persona con alcurnia pero sin dinero, y con la ilusión de adquirirlo por medio de su hija, menor de edad en el momento de su matrimonio con Patiño. El desenlace de su casamiento por conveniencia sería uno de los episodios más célebres en la historia del derecho internacional privado, por ilustrar a la perfección el problema del conflicto de las jurisdicciones y las leyes. Así lo explica un libro de derecho publicado en Francia, un libro de texto de uso muy común en las escuelas, con estas palabras: "Un boliviano se casa en Madrid con una española. Ella se vuelve boliviana por su matrimonio; la pareja vive entre Estados Unidos y Francia. Luego de muchos años de matrimonio, el marido demanda el divorcio en Francia, que le es rechazado. Lo demanda de nuevo, y lo obtiene en buenos términos para él, en México". ¿Cuál era, en efecto, la competencia de los tribunales mexicanos y franceses en los litigios internacionales? ¿Y cuál el efecto de los juicios extranjeros en México y en Francia?

A principios de los cuarenta, en Nueva York, donde vivían ambos a causa de la guerra en Europa, María Cristina de Borbón inició un juicio por abandono contra Antenor Patiño que concluyó en un convenio de reconciliación, mismo que incluía una serie de pensiones a su favor, que fueron pagadas en Manhattan. Las pensiones eran exorbitantes. María Cristina recibió medio millón de dólares de Patiño cuando accedió a reconciliarse con él, en julio de 1944, y la promesa de recibir medio millón más, siete años después, en 1951. Pero el matrimonio no tenía ya salvación. Al terminar la guerra, Patiño, que retornó a París sin ella, la requirió formalmente a través del Tribunal Civil del Sena. Ella no volvió porque

8 Pierre Mayer, Droit International Privé, París, Editions Montchrestien, 1977, p. 169. El texto comienza con estas palabras: "Más que una definición, un ejemplo tomado de la jurisprudencia francesa (se trata del caso Patiño) puede dar mejor que nada una idea de los problemas que debe resolver el derecho internacional privado". 
tenía, dijo, un litigio pendiente contra él en las cortes de Nueva York. Entonces Antenor emprendió un juicio de divorcio en Francia. Sería un proceso que duraría más de veinte años, emprendido en las cortes de París, Madrid, La Paz y Nueva York. Pero el divorcio parecía imposible.

Al cabo de una década, sin resultados a la vista, Patiño llegó a México. ¿Por qué México? Algunos pensaban que posiblemente, al reconocer al gobierno de la República Española en el exilio, México, que no tenía relaciones con el régimen del general Francisco Franco, estaba en posibilidad de ayudar a un hombre que había contraído nupcias en España bajo las leyes de la República. Otros más bien señalaban que el país era entonces un lugar ideal para conseguir un divorcio fácil y rápido, al que acudían entre otros, por ejemplo, los actores de Hollywood. El caso es que el presidente Adolfo Ruiz Cortines, al tanto de sus tribulaciones, le ofreció su apoyo para resolver el asunto de su divorcio... si hacía una buena inversión en México. Antenor Patiño, a pesar de viajar con pasaporte diplomático, estableció así su domicilio conyugal en la capital de México. Ahí, en 1956, empezó la construcción del Hotel María Isabel, un edificio muy elegante, situado en la zona más exclusiva del Paseo de la Reforma, y ahí también, una década después, concibió y planeó lo que sería su obra más espectacular: el Hotel Las Hadas, en la costa del Pacífico.

Antenor Patiño acababa de solicitar ese año de 1956 la separación de su cónyuge, María Cristina de Borbón, ante el Juzgado Séptimo de lo Civil en la Ciudad de México. Los tribunales, al aceptar su solicitud, ignoraron que el matrimonio había sido celebrado en Madrid, entre un boliviano y una española, con domicilio conyugal en París y Nueva York y con juicios de divorcio pendientes en las cortes de América y Europa. "Es un desacierto mayúsculo, ino crees?", escribió un amigo a quien sería más tarde presidente de México, Miguel de la Madrid, entonces un joven miembro de la Barra Mexicana de Abogados. ${ }^{9}$ Poco tiempo des-

9 Jorge Aurelio Carrillo, "El caso Patiño-Borbón ante el derecho internacional privado", en El Foro, abril-junio de 1961. Los pleitos por dinero eran comunes en la familia Patiño. Así, por ejemplo, el New York Herald Tribune anunciaba que Simón Patiño y su esposa Albina Rodríguez perdieron en la Suprema Corte de Estados Unidos un juicio llevado contra ambos por la señorita Alice Appiato, mucama de la señora Patiño. Le tuvieron que pagar seis mil dólares de indemnización en Nueva York, New York Herald Tribune, 16 de enero, 1943. 
pués, sin embargo, un juez de distrito falló a favor de Patiño, quien había invocado la causal de divorcio llamada abandono de hogar, pues esa causal justificaba la intervención de las cortes de México. "La regla de excepción, tratándose de juicio de divorcio por abandono de hogar", decía la sentencia de las cortes mexicanas, "es la de señalar como competente al juez del domicilio del cónyuge abandonado". ${ }^{10}$ Y Patiño estaba domiciliado en México. Era el lugar donde tenía, añadía el dictamen de la corte, "inversiones de cuantía". ${ }^{11}$

Parecía que Antenor Patiño iba a obtener en México el divorcio que tanto ansiaba. Entonces María Cristina de Borbón escribió el 3 de febrero de 1957 desde Davos, Suiza, donde pasaba las vacaciones de invierno, un cable largo y alarmado al presidente Ruiz Cortines. "Excelentísimo señor presidente", dijo:

Me permito enviarle este cable para acogerme a su internacionalmente reconocido espíritu de justicia y para rogarle que en nombre de todo lo que vuestra excelencia hace para mantener la integridad de la ley mexicana, tenga la gran bondad de interesarse para que se cumpla dicha ley mexicana imparcialmente y sin favores en cuanto a la competencia de los tribunales mexicanos con respecto a la demanda de divorcio introducida por mi esposo Antenor Patiño, contra quien hay en México investigación penal por falsificación de fechas documentos pruebas en demanda divorcio. Hasta la fecha, contra toda expectación de mi abogado licenciado Antonio Correa, las salas séptima y tercera de lo civil, más en estos últimos días el juez de distrito, han fallado a favor de mi esposo, a pesar de no haber cumplido éste en absoluto los requisitos de domicilio exigidos por ley mexicana para introducir demanda divorcio en dicha capital. ${ }^{12}$

La revisión del caso iba a ocurrir en unos días, el 9 de febrero, en la Ciudad de México. Ella no iba a poder viajar, ni tenía ganas de viajar para estar a tiempo en el país, pero su abogado la convenció de que debía escribir al presidente de la República. "El tribunal colegiado ha fijado fecha de revisión competencia para próximo día 9", explicó en el cable,

${ }^{10}$ Citado por Carrillo, op. cit.

${ }^{11}$ Loc. cit.

12 Telegrama de María Cristina de Borbón a Adolfo Ruiz Cortines, Davos, 3 de febrero, 1957 (Archivo General de la Nación, Galería 3, Caja 536, ARC 444.3/72). 
por esto me pongo en manos de vuestra excelencia para que se cumpla justicia mexicana en protección de mi hija y nietas, por quienes lucho desde hace quince años sola pero hasta ahora con éxito contra la potencia internacional de Patiño. Solamente la brevedad inesperada del plazo concedióme para la revisión ante tribunal colegiado de esta causa tan importante que afecta profundamente mi larga lucha me impide venir a tiempo a México para hacer esta petición a vuestra excelencia de manera protocolaria y me da el valor de dirigirme en esta forma rogando de corazón vuestra excelencia me perdone como madre y acepte mis más respetuosos saludos. Cristina de Borbón de Patiño. ${ }^{13}$

Patiño cumplió su palabra: empezó a hacer inversiones importantes en el país donde residía, México. Y Ruiz Cortines cumplió su promesa: ayudó a que obtuviera su divorcio. Era para él fácil hacerlo. En aquel entonces no había en México una división real entre los poderes: el Legislativo y el Judicial acataban las instrucciones del Ejecutivo. Así, en noviembre de 1958 un tribunal de México decidió el divorcio de Antenor y María Cristina. Ella entonces reaccionó en Francia, donde la justicia revirtió - o más bien, quiso revertir - la decisión tomada en México. La noticia llegó muy pronto a México. "Anulan en París el divorcio de Patiño", anunció el 2 de julio de 1959 el periódico Excélsior, para después explicar en detalle:

La primera Sala del Tribunal de Apelaciones de París dictó hoy varios mandatos judiciales en relación con las dificultades del acaudalado industrial Antenor Patiño con su esposa, María Cristina de Borbón. El primero de esos mandatos asienta que el tribunal de México no es competente para decidir, como lo hizo en noviembre pasado, el divorcio de los esposos, ya que, por una parte, éstos son de nacionalidad boliviana y, por la otra, el matrimonio se efectuó en Madrid, y España no admite el divorcio. El tribunal de París, por su parte, se declara competente porque los interesados residen en esta ciudad. ${ }^{14}$

La decisión del tribunal era sorprendente, pues apoyaba por completo la causa de María Cristina. "Además", añadía Excélsior,

${ }^{13}$ Ibid.
${ }^{14}$ Excélsior, 2 de julio, 1959. 
anuló el contrato matrimonial firmado en 1931, poco antes del matrimonio, y que preveía el régimen de separación de bienes, ya que la novia, menor de edad en esa época, no contaba con la asesoría de su tutor cuando se suscribió el contrato. El régimen aplicable es, por lo tanto, el de comunidad de bienes gananciales, régimen legal que prevalece en Bolivia. Las rentas recibidas después de 1931 por cualquiera de los esposos pasan a ser patrimonio común..$^{15}$

Fue una victoria para María Cristina de Borbón, pero una victoria en Francia, no en México. Cinco meses después, en diciembre de 1959, María Cristina perdió en México la sentencia de amparo correspondiente al juicio número 7803/58. Así, Antenor pudo seguir adelante con sus planes: contrajo matrimonio con la mujer que era su compañera desde finales de los cuarenta, la española Beatriz de Rivera. Los dos se casaron el 8 de enero de 1960 en Londres, "ambos por segunda vez", según anunció la revista Time. ${ }^{16}$ Ese matrimonio, sin embargo, no fue todavía el final de aquella historia. María Cristina lo acusó de "vivir en estado de concubinato en el hogar conyugal", lo que dio comienzo a una nueva ofensiva legal

15 Ibid. La noticia completa dice así: "París, 1 de julio. (AFP). La primera Sala del Tribunal de Apelaciones de París dictó hoy varios mandatos judiciales en relación con las dificultades del acaudalado industrial Antenor Patiño con su esposa, María Cristina de Borbón. El primero de esos mandatos asienta que el tribunal de México no es competente para decidir, como lo hizo en noviembre pasado, el divorcio de los esposos, ya que, por una parte, éstos son de nacionalidad boliviana y, por la otra, el matrimonio se efectuó en Madrid, y España no admite el divorcio. El tribunal de París, por su parte, se declara competente porque los interesados residen en esta ciudad. Confirmó, asimismo, la sentencia del Tribunal Civil del Sena, que hace un año dispuso la separación de cuerpos de los esposos Patiño, pero redujo de un millón a 500 mil francos la pensión alimentaria mensual concedida a la esposa. Además anuló el contrato matrimonial firmado en 1931, poco antes del matrimonio, y que preveía el régimen de separación de bienes, ya que la novia, menor de edad en esa época, no contaba con la asesoría de su tutor cuando se suscribió el contrato. El régimen aplicable es, por lo tanto, el de comunidad de bienes gananciales, régimen legal que prevalece en Bolivia. Las rentas recibidas después de 1931 por cualquiera de los esposos pasan a ser patrimonio común. Finalmente, el tribunal invalidó la sentencia del Tribunal del Sena que denegó en primera instancia la demanda de Patiño por 100 millones de francos por daños y prejuicios, formulada contra su esposa a la que acusaba de haberlo hecho detener el 31 de octubre de 1952 por la policía norteamericana en el aeropuerto de Nueva York". Nota del autor: 100 millones de francos franceses eran equivalentes entonces a 2 millones 500 mil pesos mexicanos.

${ }^{16}$ Time, 25 de enero, 1960. 
en su contra desde los tribunales de París. ${ }^{17}$ Pero las victorias de María Cristina en esos tribunales fueron al final victorias vanas, pues la suerte estaba ya echada a favor de Antenor en el país donde desde hacía algunos años tenía su residencia e invertía su dinero: México. El matrimonio Patiño-Borbón, en efecto, fue por fin disuelto en 1966, sin que lo pudieran evitar los tribunales de París.

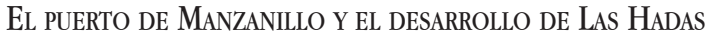

A lo largo del siglo xvis, el lugar había sido conocido como La Manzanilla. Sus pocos habitantes pescaban y colectaban perlas en la bahía, y tenían plátanos y cocoteros en las haciendas del litoral. El puerto de Manzanillo fue abierto al comercio extranjero en 1825, pero a causa de la oposición de San Blas, Mazatlán y Acapulco fue reducido a puerto de cabotaje en 1837 y luego clausurado por completo en 1842. La historia convulsiva de la segunda mitad del siglo XIX, en cambio, lo benefició, pues Manzanillo no fue controlado por los conservadores durante la Guerra de Reforma (1858-1860) ni durante la Guerra de Intervención (1862-1867). El gobierno de Estados Unidos abrió ahí un consulado en 1860. Algunos viajeros que por esas fechas visitaron la zona, como Albert Evans y John Lewis Geiger, y después Guillermo Prieto, dejaron un registro de lo que era en ese entonces este puerto de Colima. Manzanillo tenía unos 40 habitantes, que vivían de lo que ganaban descargando las naves que llegaban, "apenas siete u ocho veces al año". ${ }^{18}$ Los aduaneros estaban autorizados a vivir en la capital del estado, muy lejos del puerto, al que viajaban sólo cuando llegaba un barco. Había una calle que corría a lo largo de la playa, con tres o cuatro calles perpendiculares - muy cortas, pavimentadas con piedras de río- y con media docena de casas de adobe de un solo piso y techos de teja de dos aguas. "En 1864, Manza-

${ }^{17}$ Fallon, op. cit.

${ }^{18}$ Citado por Graciela Alcalá Moya, Con el agua hasta los aparejos, México, Ciesas, 1999, p. 179. 
nillo no tenía siquiera un embarcadero", escribió un viajero, "y sin embargo desde ahí se aprovisionaba el estado de Colima, el sur de Jalisco y una gran parte de Michoacán". ${ }^{19}$ Es interesante resaltar que, desde esos tiempos, Manzanillo era ya el puente que conectaba con el mundo al sur de la costa de Jalisco. Había un puñado de tiendas y almacenes, un cuartel, una aduana y una capitanía. Pero el puerto no dejaba de crecer. "A finales del siglo XIX", apunta el mismo viajero, "en el pueblo de Manzanillo viven alrededor de 800 familias que dependen para su subsistencia de las embarcaciones que llegan ahí cuatro veces al mes". ${ }^{20} \mathrm{Al}$ doblar el siglo, en 1903, fue construido el faro.

En 1908 fue posible enlazar por ferrocarril a México y Manzanillo, por medio de Guadalajara. El 28 de octubre de ese año llegó el primer tren de la capital con un singular pasajero: el presidente Porfirio Díaz. Fue un momento de gloria para un puerto que había sufrido ya la guerra y que sería devastado pocos años después, con la Revolución y la Cristiada. En 1914, un general mexicano, para prevenir el desembarco de los buques de guerra norteamericanos que bloqueaban el puerto, decidió, en palabras de un historiador, "prender fuego a todo el muelle, dando al traste con el progreso de Manzanillo por más de treinta años" ${ }^{21}$ Más tarde, en 1928, Manzanillo fue atacado por una columna de más de mil cristeros al mando del general Lucas Cuevas. Las tragedias políticas culminaron con una catástrofe natural el 24 de junio de 1932, cuando el poblado de Coyutlán, cerca de la laguna del mismo nombre, fue azotado por un maremoto que provocó decenas de muertos, al ser arroyado el Hotel Coyutlán.

El turismo en Manzanillo había tenido su origen ahí, en el balneario de Coyutlán. El puerto era ya relativamente grande y moderno. "Inicialmente la actividad salinera atrajo miles de trabajadores temporales", informa un estudio. "Luego, al comenzarse el trazo de las vías del ferrocarril, en 1881, se hizo necesaria la

${ }^{19}$ Ibid., p. 180.

${ }^{20}$ Loc. cit.

${ }^{21}$ José Luis Ezquerra de la Colina [coord.], Historia y futuro del desarrollo turístico y portuario del litoral en Manzanillo, Colima, Gobierno del Estado de Colima, 2006, p. 60. "El general Vigueras", agrega el autor, "fue localizado en Celaya, Guanajuato, y sometido a juicio marcial para ser ejecutado por este gran crimen a la patria". 
apertura de hoteles y casas de asistencia. Y sería el tren mismo el que, durante décadas, acarreó a miles de turistas deseosos de bañarse en la legendaria Ola Verde" ${ }^{22}$ Los bañistas usaban entonces trajes de baño negros con camisas de cuellos redondos y mangas cortas, como muestran las fotografías de la época. Eran ya bastante numerosos los turistas. En 1938, poco después del maremoto que destruyó el Hotel Coyutlán, el empresario italiano Ottavio Machetto comenzó la construcción del Hotel Playa de Santiago. Más tarde surgieron otros hoteles más, entre los que destacaban el Colonial y el Foreign Club, construido por el capitán de puerto Rafael Cordera (padre, por cierto, del destacado economista mexicano Rolando Cordera). A principios de los cincuenta, en fin, algunos empresarios descubrieron las bellezas de la península de Santiago, conocida entonces simplemente como Playa La Audiencia. Todas esas tierras formaban parte de la hacienda de Santiago, propiedad de la familia Meillón, que la vendió después a la familia Bustamante, originaria de Sonora. Luis Bustamante, en concreto, hizo lotes y construyó algunas fincas en aquella península, donde, a mediados de los sesenta, Antenor Patiño comenzaría la construcción del Hotel Las Hadas.

Manzanillo pasaba entonces por un periodo de auge. Había sido puerto piloto del programa de la Marcha hacia el Mar con el presidente Ruiz Cortines. En ese tiempo fue prolongado el rompeolas y reconstruidos los dos malecones frontales a la bahía, que hasta entonces no eran más que una burda escollera de piedra. Fue ahí donde el magnate boliviano del estaño, Antenor Patiño, emprendió la construcción del Hotel Las Hadas, al norte de Manzanillo, en la península de Santiago. Era un lugar precioso, aunque muy golpeado luego del ciclón que hacía unos meses, en 1959, había arrasado a Manzanillo. El lugar había sido declarado zona de desastre por el presidente Adolfo López Mateos y el gobernador de Colima, Rodolfo Chávez. En la bahía de Manzanillo quedaban aún hundidos los esqueletos de los buques Anita, Corzo, Jalapa, Santo Tomás y Sinaloa, así como los cascos varados y desmantelados de los guardacostas de la Armada de México.

${ }^{22}$ Ezquerra, op. cit., p. 73. 
Antenor Patiño adquirió los terrenos de la península de Santiago por medio de prestanombres - para un extranjero no había otra forma de adquirir propiedades en la costa - con el objeto de construir ahí unos bungalows. El éxito de los bungalows lo animó a financiar un proyecto más grande, que comenzó en 1966 junto con el arquitecto y urbanista de origen español José Luis Ezquerra. El Hotel Las Hadas habría de ser una obra enorme, masiva, recargada de cemento, con un costo de 33 millones de dólares. Sería un desastre para las finanzas de Patiño. Pero sería también, por un tiempo, uno de los destinos más lujosos del mundo, con un campo de golf de 18 hoyos diseñado por los hermanos Peter y Roy Dye y una marina para 120 yates encomendada a la constructora ZYS y dirigida por el ingeniero Leonardo Zeevaert Wiechers, quien acababa de construir la Torre Latinoamericana en la Ciudad de México, entonces la más alta de la República. El Hotel Las Hadas, formado por una sucesión de casas y escaleras blancas y onduladas en forma de caracol, que destellaban con la luz del sol, inconfundibles, estaba destinado a ser un sitio legendario en la costa del Pacífico.

\section{El aeropuerto internacional de Playa De Oro}

"Desde el inicio de la década de 1970", escribe Graciela Alcalá Moya, experta en el tema del litoral Pacífico de México,

Manzanillo empezó a experimentar una transformación económica que se reflejó rápidamente en su fisonomía urbana. El extremo noroeste de la bahía se convirtió en sede del desarrollo de un megaproyecto turístico impulsado por la burguesía industrial regiomontana: el proyecto Manzanillo-Las Hadas. Mientras tanto, en el extremo sureste de la bahía, el gobierno federal terminó en pocos años la construcción de una termoeléctrica para aprovisionar de energía a la ciudad y a una amplia región de tierra adentro... La inversión federal desempeñó un papel destacado en la transformación de Manzanillo. Primero se invirtió en la producción de energía eléctrica, luego en la renovación y modernización del puerto industrial de San Pedrito y, finalmente, en la reparación y construcción de carreteras 
alrededor de la bahía. Más tarde, la construcción de la carretera costera que uniría en unos cuantos años a Puerto Vallarta con Manzanillo. ${ }^{23}$

Éste es el contexto en el que el presidente Luis Echeverría apoyó la construcción del aeropuerto internacional de Playa de Oro.

El aeropuerto estaba en la mira del gobierno de México desde que, a mediados de los sesenta, Patiño comenzó la construcción de Las Hadas. Iba a ser de hecho financiado, en buena parte, con dinero de Patiño, principal interesado en dar acceso, por aire, a su emporio en la península de Santiago. La inversión habría de ser del orden de 70 millones de pesos, más o menos seis millones de dólares en esos tiempos. ${ }^{24}$

"La llegada del multimillonario boliviano Antenor Patiño", recuerda un testigo de la época, "atrajo fuertes inversionistas que exigían un buen aeropuerto internacional, para que pudieran llegar aviones de gran capacidad, sobre todo pensando el boliviano en una corriente de visitantes procedente de Europa". 25 Con ese fin, el gobernador de Colima, Pablo Silva García, tuvo varias entrevistas con el presidente Echeverría. Había ya un aeropuerto para aviones DC-3 en el ejido Salagua, cerca de Manzanillo, pero rodeado de cerros, sin reunir las condiciones de seguridad exigidas por los ingenieros de modo que ambos gobiernos, el federal y el estatal, tomaron la decisión de construir uno junto al mar, a la orilla del Pacífico. La Secretaría de Comunicaciones y Transportes tenía listo el proyecto desde 1971, pero faltaba el visto bueno del presidente Echeverría.

"Un detalle curioso que nos mostró el poder que tiene un mandatario nacional", recuerda con ingenuidad el testigo ya citado, "cuando en una de sus visitas del presidente Echeverría, al tocarle don Pablo el tema del aeropuerto internacional, bastó con llamar a su secretario de Comunicaciones y decirle: 'iHágale su aeropuerto a don Pablo!' Con estas palabras, el gran problema de

${ }^{23}$ Alcalá, op. cit. El Grupo Alfa de Monterrey, en efecto, compró a Patiño el desarrollo de Las Hadas.

${ }^{24}$ Existe una placa que tiene esta cifra inscrita en el aeropuerto de Playa de Oro.

25 Raúl Zuazo Ochoa, "Visiones personales de la Costa", en Ezquerra, op. cit., p. 53. 
Manzanillo quedó resuelto". ${ }^{26}$ En realidad, la decisión estaba ya tomada. Patiño iba a aportar una parte importante de los recursos. El aeropuerto sería terminado el mismo año en que fue concluido el desarrollo de Las Hadas en Manzanillo. El aeropuerto internacional de Playa de Oro, en efecto, fue inaugurado en octubre de 1974, unos meses después de Las Hadas. Daría servicio a todo el sur de la costa de Jalisco.

\section{LEGISLACIÓN Y SIMULACIÓN}

El Artículo 27 de la Constitución de México había sido redactado a principios de 1917, al triunfo de la Revolución, la primera revolución social del siglo Xx. México había sufrido durante ese movimiento una invasión armada a su territorio en 1914, cuando los marines atacaron el puerto de Veracruz. La rebelión y la invasión habían exacerbado los ánimos nacionalistas en el país. Es el contexto histórico que explica la naturaleza del Artículo 27 de la Constitución, que afirma así en su primer párrafo, de manera rotunda y contundente:

La propiedad de las tierras y aguas comprendidas dentro de los límites del territorio nacional, corresponden originariamente a la Nación, la cual ha tenido y tiene el derecho de transmitir el dominio de ellas a los particulares, constituyendo la propiedad privada, y añade esta advertencia: La Nación tendrá en todo tiempo el derecho de imponer a la propiedad privada las modalidades que dicte el interés público. ${ }^{27}$

La Fracción I del Artículo 27 de la Constitución era en especial relevante para los extranjeros que tenían propiedades en México, entre ellos, ahora, el magnate boliviano Antenor Patiño. Decía estas palabras: "En una faja de 100 kilómetros a lo largo de las fronteras y de 50 en las playas, por ningún motivo po-

${ }^{26}$ Ibid., p. 56.

27 Constitución Política de los Estados Unidos Mexicanos, México, Cámara de Diputados, 2005, p. 14. 
drán los extranjeros adquirir el dominio directo sobre tierras y aguas" ${ }^{28}$ La prohibición estaba originalmente justificada por cuestiones de seguridad nacional, por razones militares: era una respuesta legal a las agresiones extranjeras que había sufrido el país hasta los comienzos del siglo xx. Era una prohibición que no impedía del todo a los extranjeros, cabe decir, el aprovechamiento de las playas mexicanas, pero que les imponía la necesidad de realizar mayores trámites y que hacía más incierta y más cara la inversión, por lo que prácticamente eliminaba los incentivos que podrían tener para llevar sus recursos al país, por lo gravoso y complicado que era adquirir una propiedad en la costa.

Hasta fines de la década de los sesenta no había forma de que los extranjeros fueran propietarios de manera directa de terrenos localizados a lo largo de las playas. Pero, además, no existía aún la forma de que fueran propietarios de manera indirecta a través de los fideicomisos, como habría de estipular, hacia principios de los setenta, la Ley para Promover la Inversión Mexicana y Regular la Inversión Extranjera. Ello significó que muy pocos extranjeros - Patiño fue una de las excepciones - tuvieran el ánimo de invertir en las playas de México. La mayoría prefirió invertir en las playas de otros países.

En México no había en realidad un Estado de derecho - es decir, la ley no era respetada, sino negociada. Pero había un Estado de orden- es decir, un comportamiento previsible y racional por parte del gobierno, de acuerdo con un conjunto de reglas no escritas pero conocidas por todos. "¿En qué consistía ese Estado de orden mexicano?", habría de preguntar el investigador que planteó esta distinción.

En lo que se refiere a las reglas, relativamente claras para los actores, aunque formalmente ambiguas, éstas no dependían realmente del Código Penal, del derecho civil, del derecho comercial, aunque algunas de ellas constaban en los códigos; su aplicación no dependía realmente de los tribunales, cuyo funcionamiento estaba falseado por el autoritarismo por arriba y la corrupción por abajo. Sin embargo, en la práctica, el Estado mexicano garantizaba su aplicación a través de la amenaza del uso de la fuerza, o bien por la utilización de la fuerza. No se seguían innumerables leyes, ni gran parte de la Constitución ni los reglamentos es-

${ }^{28}$ Ibid., p. 16. 
critos, pero existían reglas no escritas, tradiciones, usos y costumbres que sí se respetaban y que sí eran previsibles. ${ }^{29}$

El Estado de orden mexicano funcionaba desde fines de la década de los cuarenta y habría de funcionar hasta finales de la década de los setenta. Coincidió con los años de gloria del llamado milagro mexicano, basado a su vez en el también llamado desarrollo estabilizador. Ese orden fue seriamente amenazado por el movimiento estudiantil que estalló en el verano de 1968, sofocado en octubre de ese año por el presidente Gustavo Díaz Ordaz, poco antes de la inauguración de los Juegos Olímpicos en la Ciudad de México. Pero se mantuvo prácticamente intacto a lo largo de la década de los setenta.

Los fideicomisos, en esa década, permitieron a los extranjeros tener propiedades en la costa y la frontera de México — es decir, en la zona restringidaa partir de 1973, durante el gobierno del presidente Luis Echeverría. La Ley para Promover la Inversión Mexicana y Regular la Inversión Extranjera, publicada el 9 de marzo de 1973 en el Diario Oficial, le dedicaba un capítulo entero a los fideicomisos, el capítulo IV, en el cual el Artículo 18 decía lo siguiente:

Se faculta a la Secretaría de Relaciones Exteriores para que autorice en cada caso la conveniencia de conceder a las instituciones de crédito, permisos para adquirir como fiduciarias el dominio de bienes inmuebles destinados a la realización de actividades industriales y turísticas en la faja de 100 kilómetros a lo largo de fronteras o en la zona de 50 kilómetros a lo largo de las playas del país, siempre que el objeto de la adquisición sea el permitir la utilización y aprovechamiento de dichos bienes a los fideicomisarios, sin constituir derechos reales sobre ellos. ${ }^{30}$

Fue un paso importante para la legislación federal reconocer por vez primera, expresamente, algo que hasta ese momento no era más que una práctica bancaria cotidiana.

${ }^{29}$ Jorge Castañeda, Somos muchos: ideas para el mañana, México, Planeta, 2004, p. 63.

30 Secretaría de Gobernación, "Ley para Promover la Inversión Mexicana y Regular la Inversión Extranjera", en Diario Oficial, 9 de marzo, 1973. 
La Ley de Inversión Extranjera, como sería conocida, permitió así la adquisición de propiedades en la costa en beneficio de los extranjeros por medio de un fideicomiso, el cual era establecido a través de un banco mexicano. El banco (o sea, el fiduciario) retenía las escrituras de la propiedad adquirida por el comprador (el fideicomitente) en favor de quien era el beneficiario del fideicomiso (el fideicomisario). La propiedad en cuestión no era parte de los bienes del banco, que era, sí, el propietario técnico del bien inmueble, pero que tenía obligaciones estatutarias de acatar las instrucciones del beneficiario concernientes a la propiedad. Los fideicomisos eran concedidos, en la ley de 1973, por un periodo de 30 años (más tarde habrían de ser 50 años), renovables por medio de la simple petición. Ellos aseguraban todos los derechos de posesión al propietario extranjero, que en cualquier momento podía vender, arrendar, hipotecar o transferir como herencia la propiedad inmobiliaria.

"Ficciones jurídicas absolutamente delirantes", las llamó un escritor. ${ }^{31}$ Lo eran. Pero los fideicomisos mostraban también el grado al que, en ausencia de un Estado de derecho, funcionaba el Estado de orden en México. Bastaba el compromiso del gobierno para que un extranjero (como Patiño) comprara un terreno, construyera un hotel y comprometiera ahí su capital en los años por venir, sin tener un título de propiedad como el que normalmente existía en su país de origen. Los extranjeros, como los mexicanos, creían en el Estado de orden en México. Y dicho orden, en ausencia de un Estado de derecho, fue suficiente para mantener un nivel mínimo de inversión extranjera en el país, a pesar de toda la retórica de la Revolución.

\section{El YeRno de PATiÑo}

Los fideicomisos impulsaron el turismo en Manzanillo y, con los años, el desarrollo y la conservación de Cuixmala, al sur de la costa de Jalisco, en un proyecto 
en el que también estuvo involucrado, indirectamente, Antenor Patiño, pues su impacto en la costa mexicana del Pacífico se prolongó por medio de su yerno, el empresario y financiero franco-inglés James Goldsmith.

Antenor Patiño y María Cristina de Borbón tuvieron dos hijas, Cristina y María Isabel. Cristina contrajo matrimonio en 1952 con Marc de Beauveau-Craon. María Isabel, por su lado, tenía 18 años cuando en 1953 conoció a James Goldsmith. Su historia de amor habría de durar menos de un año, pero estuvo desde el principio cargada de acontecimientos. En septiembre, Goldsmith anunció su intención de contraer matrimonio con ella, pero topó con los prejuicios de don Antenor. La relación siguió su curso a pesar de su oposición. En noviembre, María Isabel supo que estaba embarazada, pero su padre, ignorante del hecho, insistió en la separación: mandó a la hija a Marruecos y amenazó al pretendiente con la cárcel por tener relaciones con una menor de edad, lo cual era posible de acuerdo con la ley en Francia. Goldsmith y la hija de Patiño huyeron entonces al único lugar donde era posible casar a los menores de edad sin el consentimiento de sus padres: Escocia. El matrimonio tuvo lugar en Edimburgo. Los abogados de Patiño no lo pudieron evitar. Fue una fuga romántica y legendaria, cubierta por toda la prensa europea, que terminó en tragedia. Dos meses antes de dar a luz, en mayo de 1954, María Isabel, mientras dormía, sufrió una hemorragia cerebral masiva de la que murió sin recuperar el conocimiento unas horas después de dar a luz por cesárea a una bebita: Isabel Goldsmith Patiño, quien habría de vivir en la costa de Jalisco.

Al llegar a México a fines de los ochenta, Goldsmith asumió el papel de sucesor de Patiño. Su relación con él había sido buena hacia el final de su vida. "Muchos años después", afirma su biógrafo, "cuando las circunstancias financieras de ambos eran muy distintas, Antenor lo buscó para pedir ayuda y Jimmy actuó como si fuera parte de la familia" ${ }^{32}$ Goldsmith tenía la intención de im-

32 Fallon, op. cit., p. 106. Beatriz de Rivera, la viuda de Patiño, también subraya la buena relación que tuvieron al final con Goldsmith: "Siempre me llevé muy bien con él y tratábamos con él por su hija Isabel, nieta de mi marido, que venía mucho a Portugal", entrevista con Beatriz de Rivera, París, 13 de noviembre, 2006. La entrevista con la viuda de Patiño fue realizada por intermediación de su ayudante, la señora Marie Françoise Dhouthaut. 
pulsar varias de sus iniciativas en México. Su relación con él, por lo demás, en un país donde no conocía a nadie, era útil para hacer contactos al más alto nivel. Así lo recuerda el empresario mexicano José Carral, quien lo conoció gracias a su relación con el mundo financiero de Londres. "A mí me ve Jimmy Goldsmith, me busca para que le consiga yo una cita con Miguel de la Madrid", comenta. "Lo llevo yo con el presidente y el presidente le autoriza la compra de ese espacio enorme... La cita fue en Los Pinos. El presidente se sintió muy halagado, pues sabía que había conexión con Patiño". ${ }^{33}$ Ese "espacio enorme" al que alude Carral eran las alrededor de 10 mil hectáreas que habría de comprar Goldsmith entre Cuixmala y Chamela, para crear con ellas la Reserva de la Biosfera Chamela-Cuixmala. El presidente de la Madrid tenía razones personales para estar agradecido con Goldsmith, quien pensaba invertir en su estado natal, Colima, al igual que lo había hecho antes don Antenor. Ello beneficiaba uno de los proyectos consentidos de su gobierno: el Plan Colima. Goldsmith, a su vez, valoraba la importancia de su vínculo con Patiño, que lo consolidaba en México. Pocos años más tarde habría de distribuir entre los medios una nota biográfica que decía así: "Presencia activa en México desde 1987, en relevo de su suegro, don Antenor Patiño, inversionista en México desde los años sesenta hasta los años ochenta, creador del Hotel María Isabel en la Ciudad de México, del Hotel Las Hadas en Manzanillo, Colima, y del proyecto Hacienda de San Antonio en San Antonio, Colima" ${ }^{34}$

La hacienda de San Antonio era una propiedad situada en las tierras más templadas del municipio de Comala, sobre las faldas del Volcán de Fuego, 30 km al norte de Colima. Había sido propiedad de un alemán que llegó a la región a sembrar café a fines del siglo xix. El lugar era espectacular, poblado de lagos, valles y bosques de nogales y cedros, dominados por la silueta del volcán. Su entorno natural, de hecho, estaba protegido desde principios del siglo xx. En 1920, el Diario Oficial publicó que, por causa de interés público, se decretaba zona de protección forestal y refugio de fauna silvestre el área conocida como El Ja-

33 Entrevista con José Carral, México, 24 de julio, 2006.

${ }^{34}$ Perfil de Sir James Goldsmith que circuló entre la prensa en México. Archivo de Luis de Rivera. 
balí, en Colima. Aquel mandato fue ratificado más tarde, en 1981, por otro decreto que protegía una superficie de 5178 hectáreas en el municipio de Comala. Este decreto, firmado por el presidente López Portillo, consideraba "que en la región conocida como El Jabalí, que se localiza en el municipio de Comala, estado de Colima, existen tres lagunas permanentes, arroyos que provienen de las partes altas del volcán de Colima, bosques de nogal, cedro, fresno, encino y pino, todo lo cual, además de su extraordinaria belleza natural, constituye un refugio para la fauna silvestre", y consideraba, asimismo, "que por su atractivo escénico faunístico en el ambiente natural, la mencionada zona es propicia para fomentar el turismo nacional y extranjero". ${ }^{35}$ Así, el decreto que protegía la región establecía al más alto nivel que la zona, favorable al turismo, estaría a salvo de la destrucción.

Antenor Patiño había comprado la propiedad en 1973, con la idea de reconstruir la hacienda para hacer ahí un hotel de montaña que complementara el que ya tenía en la playa, Las Hadas. Más adelante, en 1980, creó la empresa Hacienda de San Antonio S. A. de C. V., la cual aparecía como propietaria de 510 hectáreas en el municipio de Comala. Patiño fue el primer presidente de su consejo de administración. Reubicó las casas de los peones que trabajaban en la propiedad y construyó una pista de aterrizaje en El Jabalí, y comenzó después a restaurar el casco de la hacienda junto con el arquitecto Mauricio Romano. La hacienda, caída en la ruina desde fines de los veinte, habría de resucitar durante los ochenta, luego de la muerte de don Antenor. Goldsmith le compró la propiedad en 1987 y sucedió a Patiño en la presidencia del consejo de administración de la Hacienda de San Antonio S. A. de C.V., que adoptó la forma jurídica que describió él mismo en el perfil biográfico que pondría a circular en México: "fideicomiso turístico-ecológico ubicado en el municipio de Comala, Colima". ${ }^{6}$ En aquel perfil subrayó su relación con Patiño: "El señor Goldsmith tomó el re-

35 Secretaría de Agricultura y Recursos Hidráulicos, "Decreto que por causa de interés público se establece zona de protección forestal, y refugio de la fauna silvestre, la región conocida como El Jabalí, localizada en el Municipio de Comala, Colima, dentro de una superficie aproximada de 5178-5600 hectáreas", en Diario Oficial, 14 de agosto, 1981.

${ }^{36}$ Perfil de Sir James Goldsmith que circuló entre la prensa en México. 
levo de su suegro, don Antenor Patiño, que había iniciado el proyecto de San Antonio en los años setenta". ${ }^{37} Y$ anunció la cantidad que había invertido en la propiedad, así como el número de sus trabajadores: "Inversión: más de 12 millones de dólares. Empleos directos: 204". 38

Pero San Antonio fue algo más para James Goldsmith pues el proyecto ecológico y turístico que impulsó ahí, inspirado por don Antenor, prefiguró lo que haría después en la costa de Jalisco. Goldsmith abrazaba la causa de la ecología desde mediados de los setenta. Había recibido en 1976 ("por sus servicios a las exportaciones y a la ecología") el título de Caballero. ${ }^{39}$ Pero su conversión vino después, a principios de los noventa. Sir James creó en esos años la Goldsmith Charitable Foundation, uno de cuyos objetivos era dar apoyo a proyectos para conservar el medio ambiente, en Europa y América. Más tarde publicó un libro en el que haría una crítica minuciosa de la economía capitalista, por sus efectos desastrosos sobre la sociedad y la ecología. El libro fue muy leído en Francia (Le piège) y en Inglaterra (The Trap), países en los que residió Goldsmith. Plaza \& Janés lo publicó en México con el título de La trampa.

Goldsmith era ya un empresario que dedicaba su fortuna y su energía a la defensa del medio ambiente cuando adquirió los terrenos que donaría a la Reserva de la Biosfera Chamela-Cuixmala. Para impulsar su proyecto de conservación en la costa de Jalisco, Goldsmith creó, el 25 de mayo de 1988, la Fundación Ecológica de Cuixmala A. C. Su razón social era "llevar a cabo todo tipo de actividades relacionadas con la preservación y restauración del equilibrio ecológico de las especies de animales y vegetales del estado de Jalisco", así como también "promover ante las autoridades competentes el decretar y/o emitir disposiciones legales que tengan por objeto la protección del sistema ecológico del estado de Jalisco" y "promover y llevar a cabo estudios e investigaciones tendientes a mejorar el conocimiento del sistema ecológico del estado de Jalisco" . ${ }^{40}$ La Fun-

\footnotetext{
37 Ibid.

38 Ibid.

39 Sally Bedell Smith, "Billionaire with a Cause", en Vanity Fair, mayo de 1997.

${ }^{40}$ Acta constitutiva de la asociación civil Fundación Ecológica de Cuixmala A. C., 30 de julio, 1988 (expediente 134/88). Registro Público de la Propiedad de Autlán.
} 
dación adquirió alrededor de 10 mil hectáreas de selva en la montaña, las cuales pertenecían a decenas de propietarios. Uno de sus objetivos era, en efecto, "la adquisición mediante compraventa, arrendamiento, aportación, cesión de derechos o mediante cualquier otro título legal de propiedad o posesión de bienes muebles o inmuebles que en cualquier forma se relacionen con el objeto de esta asociación". ${ }^{41}$ Ese era el propósito: adquirir una extensión de selva suficientemente grande para crear, ahí, una reserva de la biosfera.

La Fundación Ecológica de Cuixmala contó desde el principio con el apoyo de la Estación de la unam en Chamela, dos de cuyos biólogos elaboraron el estudio base para la Reserva. Así comenzó a ser concebida la Reserva de la Biosfera Chamela-Cuixmala, que habría de tener, más tarde, un impacto tan profundo en la costa de Jalisco. La superficie de la Reserva estaba integrada por terrenos privados, aportados, en orden de importancia, por la Fundación Ecológica de Cuixmala, la Universidad Nacional Autónoma de México y la Universidad de Guadalajara. "Los propietarios y poseedores de predios ubicados dentro de la Reserva de la Biosfera Chamela-Cuixmala están obligados a la conservación del área", indicaba el Artículo Séptimo del decreto con que nació la Reserva, pero el Artículo Décimo primero añadía lo siguiente: "En la zona de amortiguamiento de la Reserva podrán autorizarse proyectos de desarrollo turístico de baja intensidad, previa autorización de la manifestación de impacto ambiental respectiva y cumplimiento de las disposiciones jurídicas aplicables" . ${ }^{22}$ Era una concesión a los grupos interesados en invertir en esa zona, sobre todo alrededor de la laguna de Playa Careyes. Esos grupos estaban también, curiosamente, relacionados por sus lazos familiares con don Antenor Patiño. El desarrollo del turismo no había sido cancelado. Pero lo cierto es que aquella parte de la costa había quedado blindada por la ecología contra los desarrolladores.

${ }^{41}$ Ibid.

${ }^{42}$ Secretaría de Desarrollo Social, "Decreto por el que se declara área natural protegida, con carácter de reserva de la biosfera, la región conocida como Chamela-Cuixmala, ubicada en el municipio de La Huerta, Jalisco", en Diario Oficial, 30 de diciembre, 1993. 


\section{CONCLUSIÓN}

La historia descrita en este trabajo muestra que la transformación de la fisonomía de la costa de Colima y Jalisco (es decir, sus hoteles y sus marinas, así como sus reservas naturales) fue determinada en gran medida por motivos sumamente personales de los personajes involucrados en su desarrollo y conservación, esencialmente dos extranjeros: el empresario boliviano Antenor Patiño y su yerno, el financiero franco-inglés James Goldsmith. Muestra también que el proceso mediante el cual tuvo lugar esta transformación, inspirado como estuvo por motivos personales, no fue un proceso racional sino caprichoso.

Entre los motivos en cuestión resalta la inversión multimillonaria que para justificar su domicilio conyugal en México, necesario a su vez para conseguir el divorcio de su primera esposa, tuvo que hacer Antenor Patiño en la costa mexicana del Pacífico. Patiño, en efecto, financió el aeropuerto de Playa de Oro durante la construcción del Hotel Las Hadas, aeropuerto que hasta la fecha da servicio a Colima y al sur de la costa de Jalisco, y fue el imán que atrajo al hombre que moldeó esa zona, James Goldsmith, marido de su hija menor, quien, además de consolidar el proyecto ecológico-turístico del parque natural El Jabalí en Colima, inspirado por Patiño, adquirió los terrenos que formaron la Reserva de la Biosfera Chamela-Cuixmala, la cual desde 1993 determina el ritmo y la forma del crecimiento del centro de la costa de Jalisco. Para transformar así el paisaje, ambos tuvieron que sortear los obstáculos legales que había en México para la inversión extranjera en las playas de toda la República.

Desde mediados de los setenta, en parte con el empuje del Hotel Las Hadas, pero también en parte con la protección del entorno natural de El Jabalí, el turismo y la conservación fueron dos actividades predominantes en esa zona del occidente de México. La tensión entre las dos, conservación y turismo, provocó un choque que culminó en 1993 con el decreto de la Reserva de la Biosfera Chamela-Cuixmala. El desarrollo fue contenido, así, por la conservación. Las vías de comunicación inauguradas en los setenta, como el aeropuerto, hicieron posible que llegaran los empresarios que promovieron el desarrollo de esas tierras del país pero también, paradójicamente, que penetraran por ella los agentes que 
las habrían de volver a cerrar, para su conservación. La conservación ecológica predominó al final sobre el desarrollo turístico en el centro de la costa de Jalisco, gracias al decreto presidencial de la Reserva de la Biosfera Chamela-Cuixmala.

Recibido: 7 de junio, 2012. Aceptado: 27 de julio, 2012.

BiBLIOGRAFÍA

Acta constitutiva de la asociación civil Fundación Ecológica de Cuixmala A.C., 30 de julio, 1988 (expediente 134/88). Registro Público de la Propiedad de Autlán.

Alcalá Moya, Graciela, "Los puertos, la actividad turística y las pesquerías en el Occidente de México: una visión de conjunto”, en Revista Universidad de Guadalajara, febrero de 1994. , Con el agua hasta los aparejos, México, Ciesas, 1999.

Álvarez, José Rogelio, Jalisco: nueve ensayos, Guadalajara, Tlacuilo, 1964. , Guadalajara y sus caminos al mar, León, Everest, 1984.

BeDELL SMITH, SALLY, "Billionaire with a Cause", en Vanity Fair, mayo de 1997.

Brand, Donald D., Coastal Study of Southwest Mexico, 2 ts., Austin, Universidad de Texas, 1958.

Carrasco, Manoel, Simón I. Patiño: o magnata do estanbo, Río de Janeiro, Ediçoes Bloch, 1972.

Carrillo, Jorge Aurelio, "El caso Patiño-Borbón ante el derecho internacional privado", en El Foro, abril-junio de 1961.

CASTAÑEDA, Jorge, Somos muchos: ideas para el mañana, México, Planeta, 2004. Ceballos, Gerardo, AlberTo SzÉKely et al., Programa de manejo de la Reserva de la Biosfera Chamela-Cuixmala, México, Semarnap, 1999.

CÉspedes, Augusto, Metal del diablo, La Habana, Casa de las Américas, 1965. 
Constitución Política de los Estados Unidos Mexicanos, México, Cámara de Diputados, 2005.

Dau, Alfonso [coord.], Jalisco: estrategia de desarrollo, Guadalajara, Gobierno del Estado de Jalisco, 1973.

EZquerRa DE LA Colina, José Luis [coord.], Historia y futuro del desarrollo turístico y portuario del litoral en Manzanillo, Colima, Gobierno del Estado de Colima, 2006.

Fallon, Ivan, BILLIONAIRE: The Life and Times of Sir James Goldsmith, Londres, Arrow Books, 1992.

FEBVRE, LuCIEN, La terre et l'évolution bumaine: introduction géographique à l'bistoire, París, La Renaissance du Livre, 1922.

Fregoso Valencia, Humberto, Cibuatlán: datos para su bistoria, Barra de Navidad, Edición privada, 2005.

Goldsmith, James, La Trampa, México, Plaza \& Janés, 1995.

MAYER, PIERRE, Droit International Privé, París, Editions Montchrestien, 1977.

Muriè, José María, Breve historia de Jalisco, México, FCE, 2005.

Perfil de Sir James Goldsmith que circuló entre la prensa en México.

Secretaría de Agricultura y Recursos Hidráulicos, "Decreto que por causa de interés público se establece zona de protección forestal, y refugio de la fauna silvestre, la región conocida como El Jabalí, localizada en el Municipio de Comala, Colima, dentro de una superficie aproximada de 5,178-56-00 hectáreas", en Diario Oficial, 14 de agosto, 1981.

Secretaría de Desarrollo Social, "Decreto por el que se declara área natural protegida, con carácter de reserva de la biosfera, la región conocida como Chamela-Cuixmala, ubicada en el municipio de La Huerta, Jalisco", en Diario Oficial, 30 de diciembre, 1993.

Secretaría de Gobernación, "Ley para Promover la Inversión Mexicana y Regular la Inversión Extranjera”, en Diario Oficial, 9 de marzo, 1973.

Wansell, Geoffrey, Tycoon: The Life of James Goldsmith, Londres, Grafton Books, 1987.

YáÑez, Agustín, "Multiplicación de Jalisco", Barra de Navidad: estudio de un área, México, offset Diana, 1958. 